\title{
Why there is Basically only one Form of Political Trust
}

British Journal of Politics and International Relations, 13(2), 269-275.

\author{
S U M M A R Y
}

Political trust remains one of the most elusive topics in political science research. On the one hand, we expect that critical citizens display some form of distrust toward those who hold power within a political system. Some authors have even claimed that expressing trust in politicians is even logically inconsistent. While it makes sense to expect that most people will express trust toward their relatives, partners and friends, there is much less to be said about expressing trust toward, e.g., the Prime Minister. Given the fact that most citizens do not know the Prime Minister personally, in general they will not have access to sufficient information about the personal trustworthiness of the Prime Minister to arrive at a qualified judgement (Hardin 1993). On the other hand, most political scientists will, explicitly or implicitly, agree with the fact that the measurement of political trust can function as a thermometer to assess the health and vitality of a political system. Low or declining levels of political trust usually only spell trouble for democratic stability. The fact that trust in the US President, e.g., has been caught in a downward spiral since the early 1970's limits the capacity 
of the American political system to provide more public goods to the population (Hetherington 2004).

Apparently, political trust still functions as an important resource for the legitimacy of political systems, as Almond and Verba argued almost half a century ago in their classic work on The Civic Culture (1963). Given the salience and the continuing elusiveness of political trust for the current academic debate, it is clear that the article by Justin Fisher, Jennifer van Heerde and Andrew Tucker (2010) in this journal is of paramount importance. Fisher et al. criticize the standard measurement of political trust as a simple one-dimensional construct. Based on an extensive review of the literature, they argue that at least three forms of political trust should be distinguished, both for theoretical as for empirical reasons. Strategic trust results from a judgement about the trustworthiness of the other actor, and an assessment of the odds that one's own legitimate interests will be harmed or not by this actor. Moral trust, on the other hand, focuses on the moral commitment to be trustworthy, and the expectation that this imperative will equally apply to other members of society. Deliberative trust, finally, focuses on deliberative and representative procedures, that will help to ensure proper conduct by political decision-makers. The authors subsequently use recent data sources to demonstrate that these various forms of trust are related to trust in political parties and trust in institutions. The conclusion is that "forms of trust may vary by institution" (Fisher et al., 2010, 182).

Fisher and his colleagues have made an extremely important and well-argued contribution to the debate. Within the literature, political trust has been a topic that does not receive sufficient theoretical consideration. Most scholars simply use the standard survey items on "trust in government', without questioning their validity, or even wondering what political trust actually refers to, or what place the concept could have in democratic society. The contribution of Fisher et al. therefore needs to be applauded. Nevertheless, my claim is that their distinction between three forms of political trust is not well grounded, both conceptually as empirically and this distinction could misguide the future academic debate. I want to address these concerns before drawing some conclusions on what this implies for our understanding of the way citizens make judgements about the trustworthiness of politicians and the political system. I agree that in an ideal world, the basic tenet of Fisher et al. would be correct: citizens should arrive at a different trust decision for each and every political institution. In practice, however, we can observe that all these different evaluations are being summarized into one comprehensive and one-dimensional expression of political trust. A likely explanation for this pattern is that political trust can be conceptualized as a 
comprehensive evaluation of the political culture that is prevailing within a political system and not as an evaluation of each and every actor individually.

\section{$(\ldots)$}

We replicate the analysis by the authors on the March 2009 panel of the British Election Study $(n=1,080)$.

Table 1. Factor analysis of Political Trust Items in British Election Study 2009

\begin{tabular}{|c|c|c|c|c|}
\hline & \multicolumn{2}{|c|}{ Model I } & \multicolumn{2}{|c|}{ Model II } \\
\hline & Factor 1 & Factor 2 & Factor 1 & Factor 2 \\
\hline I can find a political party that reflects my views & .549 & .210 & .542 & .179 \\
\hline The winning party usually reflects some of my views & .517 & .274 & .478 & .378 \\
\hline $\begin{array}{l}\text { When parties win power, they usually do what they say } \\
\text { they would }\end{array}$ & .709 & -.344 & .728 & -.221 \\
\hline The issues politicians consider, reflect my concerns & 638 & .278 & .604 & .348 \\
\hline $\begin{array}{l}\text { Politicians discuss the issues that are most important for } \\
\text { Britain }\end{array}$ & .717 & .010 & .690 & .164 \\
\hline Party activists are just like me & 619 & -.244 & .620 & -.106 \\
\hline $\begin{array}{l}\text { Parties bring together different kind of people to achieve } \\
\text { common goals }\end{array}$ & 667 & -.034 & .641 & .140 \\
\hline We need politicians that are able to debate complex issues & 638 & .295 & .605 & .354 \\
\hline Politicians consider my concerns & .757 & -.271 & .765 & -.137 \\
\hline $\begin{array}{l}\text { It is more important that elections are democratic, than } \\
\text { which party gains power }\end{array}$ & .256 & .672 & .195 & 619 \\
\hline $\begin{array}{l}\text { Parties represent their supporters, not just those who fund } \\
\text { them }\end{array}$ & .701 & -.195 & 697 & -.040 \\
\hline $\begin{array}{l}\text { Politicians discussing the issue is more important to me } \\
\text { than the outcome }\end{array}$ & .443 & .380 & .407 & .357 \\
\hline Politicians deliver on their promises & .742 & -.284 & .768 & -.200 \\
\hline Trust in Political parties & & & .725 & -.448 \\
\hline Trust in Politicians & & & .733 & -.454 \\
\hline Eigen Value & 5.11 & 1.25 & 5.98 & 1.51 \\
\hline Explained Variance & 39.27 & 9.62 & 39.86 & 10.04 \\
\hline
\end{tabular}

Entries are the result of a Principal Component Analysis, on the March 2009 panel of the British Election Study $(\mathrm{n}=1,018)$.

First, in Model I, we bring together the twelve items that Fisher et al. use to construct their three forms of political trust. The results unequivocally demonstrate that there are no three 
distinct factors. Basically, 11 of the 12 items load on the first strong factor (Eigen value 5.11), providing strong evidence for the one-dimensional character of political trust. Only the item claiming that the most important thing about elections is that they must be democratic, loads quite strongly on a second (but much less powerful: Eigen value of 1.25) factor. This is the kind of analysis that Fisher et al. should have done to support their claim that there are three distinct forms, but the result is clearly that political trust basically is one-dimensional.

In Model II we go a step further, by also including the two dependent variables they use in the same factor analysis. Again the results are easy to interpret: the two 'dependent' variables are just an element of the same latent concept. Trust in political parties loads unequivocally on this scale, just as the belief that political parties will deliver on their promises. As such, the relation between these variables is tautological.

We can demonstrate this also in a different way. We follow the logic of the authors, and we use a regression model to explain trust in political parties, by using the belief that parties will do what they say as an independent variable. We include this as the only independent variable in our model. The result is an incredibly strong model with a standardized regression coefficient of .49 , a t-value of 17.4 and 24 per cent explained variance. Let's say that everyone who is familiar with survey research would be highly cautious if one single item took care of 24 per cent explained variance, as this usually means that the relation one investigates is tautological, not causal.

\section{$(\ldots)$}

There are two likely explanations for the apparent one-dimensionality of political trust. The first one results from a deficiency model: it is assumed that citizens are simply too 'lazy' or not sufficiently knowledgeable to form a distinct judgement on all the institutions listed in the standard battery. Since they are cognitive misers, they just focus on the person or institution that is most often featured in the news (the Prime Minister, or the President) and subsequently generalize this attitude toward all kind of political institutions without bothering further trying to assess whether this generalization is founded.

A second possible explanation, however, could be that citizens can sincerely believe that the trustworthiness of all political institutions will overlap to some extent. This heuristic device is not unlikely, given the fact that political systems basically have one joint political culture, and 
this culture determines whether politicians are trustworthy or not. I might disagree with the ideas of a specific political party, but it is highly unlikely that all MP's of this party would be corrupt, while all the MP's of other parties are not. All of them share the norms of the same political culture, and therefore they will behave in the same corrupt or trustworthy manner. Self-evidently politicians from a major ruling party are more likely to be targeted by bribery efforts or corruption than politicians from a fringe opposition party, but basically we can expect that these opposition politicians would do exactly the same, given the opportunity to do so. Therefore, as a heuristic short cut, it makes sense to arrive at a comprehensive judgement on political trust, since we know the behaviour of politicians and institutions will be determined mainly by the political culture, which is a system characteristic, not a characteristic of the specific institution.

At first sight, we have no reason to prefer one of the two explanations for the onedimensionality of political trust scales. If the first line of reasoning would be more convincing, however, we should be able to observe that the one-dimensionality of the political trust battery is weakened by political and cognitive sophistication. Knowledgeable citizens would judge every institution on its own merits, less knowledgeable citizens would simply lump them all together. Following this line of reasoning, we would expect a negative relation between the education level of respondents and the one-dimensionality of their answers on this scale. This however, proves not to be the case, even on the contrary. If we again refer to the European Social Survey ( $3{ }^{\text {rd }}$ wave), we can observe that the one-dimensionality of the scale even slightly increases with education level. While among the lowest educated the scale has an Eigen value of 4.32 (with 61.8 per cent explained variance), these figures are even a bit higher among those who pursued higher education. It can be safely assumed, therefore that the one-dimensionality of the scale is not caused by a lack of political knowledge, political interest or political sophistication. The one-dimensionality of the scale is clearly not the result of some sort of cognitive deficiency.

This renders the second explanation more plausible: political trust can be considered as a comprehensive assessment of the political culture that is prevalent within a political system, and that is expected to guide the future behavior of all political actors. This expectation is not without any empirical grounds. Looking at studies on corruption, there are no examples of countries where Members of Parliament would be corrupt but the government is clean. The degree of trustworthiness is therefore not an individual characteristic of a person, not even of a political party or an institution but of the political system as a whole. As such it makes sense 
that my opinion on various actors loads on a single latent variable. Given the fact that political culture is a system characteristic, and unless one can show me a country where ministers are very corrupt, and Members of Parliament are very honest, there is no reason to differentiate my trust judgement for those two political institutions. Citizens most likely will not have read the work by Almond and Verba on the importance of political culture, but it is clear that in their assessment of political institutions they apply the same logic on the importance of norms guiding the behaviour of political decision makers. 